\title{
Análise de dados estatísticos para tomadas de decisão em conselhos de classe
}

\author{
ANALYSIS OF STATISTICAL DATA FOR DECISION MAKING IN CLASS COUNCILS \\ Bruno César Ribeiro da Silva, ${ }^{1}$, Aldrin Gustavo Martins², Cássia do Carmo Pires Fernandes ${ }^{3}$ \\ 1 - Departamento de Mineração, IFMG/Campus Congonhas \\ 2 - Departamento de Mineração, IFMg/Campus Congonhas \\ 3 - Professora no Ensino Básico, Técnico e Tecnológico do IfMg/Campus Ponte Nova \\ E-MAIL: BRUN0.RIBEIR0@IFMG.EDU.BR; ALDRIN.MARTINS@IFMG.EDU.BR; CASSIA.PIRES@IFMG.EDU.BR
}

\begin{abstract}
This work proposes a methodology to be used in class councils as a way to guide decision making on passing or failing of students who did not reach the minimum passing grade in a given discipline. A survey and analysis of the information base of the disciplines of the technical course in mining was carried out, in order to statistically calculate student grades. From the analysis of the data, a mapping is proposed, containing hypotheses about the students' level of learning. Thus, it tends to establish a more coherent and regular board decision-making, over the years.
\end{abstract}

Resumo: Este trabalho propõe uma metodologia para ser utilizada nos conselhos de classe como forma de orientar a tomada de decisão sobre reprovações de alunos que não alcançaram a pontuação mínima para aprovação em determinada disciplina. Foi realizado um levantamento e análise da base de informações das disciplinas do curso Técnico em Mineração do Instituto Federal de Minas Gerais Campus Congonhas na modalidade subsequente entre os anos de 2015 a 2019 para calcular estatísticas das notas dos alunos. A partir da análise dos dados, é proposto um mapeamento contendo hipóteses sobre o nível de aprendizado dos alunos. Assim tende-se a estabelecer uma tomada de decisão do conselho mais coerente e regular ao longo dos anos na perspectiva de um processo de avaliação a serviço da aprendizagem.

\section{Introdução}

O Conselho de Classe é um espaço coletivo de avaliação da aprendizagem discente; portanto, o professor não deveria decidir sozinho sobre a promoção e/ou reprovação do aluno, sendo prudente a análise de diferentes atores, como da equipe pedagógica e dos demais professores, com o objetivo da melhoria da aprendizagem do aluno (Magnata \& dos Santos, 2015).

A partir de tal perspectiva conceitual, o Conselho de Classe realizado em dezembro de 2019 no Instituto Federal de Minas Gerais (IFMG), Campus Congonhas, referente aos cursos técnicos, se constituiu como fonte de observações sobre os comportamentos de seus participantes, professores, psicólogo e pedagogos para o presente trabalho. Uma das discussões, em especial, foi sobre dois alunos que não tiveram comportamento adequado ao longo do ano letivo e, por esse motivo, apesar de restar menos de 2 pontos para a aprovação direta, eles tiveram que fazer a prova de recuperação,
Citation/Citação: Silva, B. C. R. da, Martins, A. G., \& Fernandes, C. C. P. (2020). Análise de dados estatísticos para tomadas de decisão em conselhos de classe. Terræ Didatica, 16, 1-7, e020039. doi: 10.20396/td.v16i0.8660629

Keywords: Evaluation Process, Descriptive Statistics, Education.

Palavras-chave: Processo de Avaliação, Estatística Descritiva, Educação.

Manuscript/Manuscrito:

Received/Recebido: 27/07/2020

Revised/Corrigido: 13/09/2020

Accepted/Aceito: 25/09/2020

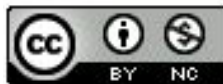

e um terceiro aluno foi aprovado direto faltando 2,5 pontos. Considerando a dimensão formativa e processual da avaliação da aprendizagem, é importante repensar o fato de alunos com pontuações mais próximas da nota de aprovação serem reprovados, enquanto outro, com nota mais distante da nota mínima ser aprovado na mesma disciplina. Observou-se, também, que vários alunos foram reprovados em uma disciplina por menos de 5 pontos, sendo que a média histórica das notas dessa disciplina é igual a 62 pontos. Assim, algumas dúvidas começam a surgir: será que um aluno em determinada disciplina mais "difícil" com nota um pouco inferior ao critério de aprovação adquiriu o conhecimento básico para avançar no curso? Ou será que a metodologia de ensino e as estratégias avaliativas adotadas pelo docente criaram dificuldades na aprendizagem do discente? Qual seria o sentido de uma avaliação justa quanto ao julgamento de valor e mérito para definir quem aprendeu e quem não aprendeu o suficiente para ser aprovado? 
Cabe aqui recorrer a origem da palavra "avaliar", que vem da composição a-valere, em latim, que significa "dar valor a...". Já a definição de "avaliação" é mais complexa, como assinala Ristoff (2003) no estudo intitulado "Algumas definições de avaliação". O autor alerta que, historicamente, existe uma corrente majoritária e uma principal discordância quanto ao que seria avaliação. A ideia predominante na literatura é creditada à Joint Committee on Standards for Educational Evaluation (1981), formada por um conjunto de universidades americanas, em que avaliação é "a investigação sistemática do valor e do mérito de algum objeto" - que pode ser um programa, algum material instrucional, projeto, entre outros. Mas o que é valor (worth)? E o que é mérito (merit)? Objetivando entender esses conceitos, o autor os traduz como "valor de mercado" e "valor intrínseco". Para o Joint Committee, avaliar é uma atividade sistemática de pesquisa, de fundamentação e de conhecimento "do objeto", e não uma simples opinião e julgamento aleatórios. No caso das escolas, "o objeto" é a vida acadêmica de cada aluno.

Embora muitas decisões sejam baseadas em critérios subjetivos, como comportamental, grau de comprometimento dos discentes e docentes, dificuldades pregressas dos estudantes, ao menos um critério objetivo, pautado em análise estatística pode ser realizada, norteando os atores do Conselho de Classe a decidirem de forma coerente com o propósito formativo da educação escolar.

A presente investigação objetiva propor uma metodologia para ser utilizada nos conselhos de classe como forma de orientar as tomadas de decisões sobre reprovações de alunos que não alcançaram a pontuação mínima para serem aprovados em determinada disciplina. Foi realizado um levantamento e análise da base de informações das disciplinas do curso Técnico em Mineração do Instituto Federal de Minas Gerais Campus Congonhas, para calcular estatisticamente as notas dos alunos em cada disciplina. A partir da análise dos dados, é proposto um mapeamento contendo hipóteses sobre o nível de aprendizado dos alunos.

\section{Conselho de classe: breve revisão da literatura}

Em 2205 a.C. o imperador Chinês o Grande "Shun" utilizava exames como forma de avaliação para selecionar homens capacitados para servir ao Estado (Depresbiteris, 1989).
Países da Europa, como Portugal e França, estabelecem uma ciência do estudo sistemático dos exames, com relação a atribuição de notas e sobre os comportamentos dos examinadores e examinados (De Landsheere, 1976). De acordo com Luckesi (1995), no Brasil, avaliar por meio de provas e exames é uma herança dos jesuítas, desde 1599, com ênfase à memorização, à retorica, à redação, à leitura de clássicos e à arte cênica, sendo os alunos premiados de acordo com a disciplina e rendimento escolar, provável herança da palmatória. Muitos pesquisadores relatam que o sistema de aferição de notas é somente um processo burocrático que serve apenas para os pais acompanharem a vida escolar de seus filhos, aos analisarem os boletins, não garantindo, por outro lado, o aprendizado ou a aquisição dos conhecimentos para possibilitar uma transformação na vida do aluno e, por conseguinte, na sociedade (Ledesma \& Schon, 2008).

Historicamente, no Brasil, a introdução do Conselho de Classe ocorreu em torno do ano de 1959, quando foram realizadas experiências-piloto no Colégio de Aplicação da Universidade Federal do Rio de Janeiro. Esse processo foi expandido para estados da nação e após a promulgação da Lei ${ }^{\circ}$ $5.692 / 71$, foi disseminado de forma gradativa para todo o país (Rocha, 1986). A partir da década de 1990, quando começaram a ocorrer os registros dos conselhos em planilhas eletrônicas com a finalidade de agilizar o armazenamento das decisões, poucos sabiam dominar o uso dos computadores para resgatar tais informações, dificultando pesquisas sobre cultura escolar (Leite, 2012).

De acordo com Oliveira \& Medeiros (2018), os docentes, por terem uma visão compartimentada dos alunos, adotam apenas o critério da nota mínima para aprovação, como exemplo a nota 60 sendo um corte da normalidade, sendo que outras questões deveriam ser levadas em consideração como, especificamente, se o aluno corresponde ou não a padrões e condutas esperadas (Oliveira \& Medeiros, 2018). Portanto, a nota mínima é apenas um dos critérios de aprovação, sendo que conforme a conduta do aluno, uma nota inferior a 60 pode ser aprovação por critérios abstratos. $\mathrm{O}$ conselho tem sido utilizado como instrumento de seleção dos alunos, a partir de padrões estabelecidos pela instituição de ensino e/ou pelo professor, estabelecendo o fracasso escolar (Mattos, 2005, Guerra, 2006). Ainda de acordo com a Lei de Diretrizes e Bases da Educação Nacional (LDB), artigo 14, inciso II: 
Mediante esse quadro, é fundamental aos seus agentes, responsáveis por toda dinâmica de desenvolvimento do projeto educativo da escola, buscar novos instrumentos que possam contemplar o processo ensino-aprendizagem dos discentes, bem como solicitar a participação dos pais, alunos e gestores para que todos possam compartilhar na tomada de decisões coletivamente e contribuir para uma melhor qualidade do ensino (Brasil, 1996)

Carneiro (2016) enfatiza o Conselho de Classe como um período de tensão para alunos, professores e a comunidade escolar em geral, com o professor assumindo quase sempre o papel de julgador, mas a decisão deve ter um respaldo coletivo de todos que participam do processo, sempre com ética e responsabilidade, facilitando a decisão do docente, uma vez que a responsabilidade sobre a análise da promoção do discente em discussão é compartilhada com os demais docentes, ou vários olhares.

Foi possível constatar, também, que a aprovação de um aluno, ainda que não tenha chegado à média de uma disciplina, é viável quando apresenta evolução durante o ano letivo, é assíduo, mostra interesse e, também, a partir do bom desempenho em outras disciplinas, o que evidencia uma dificuldade específica numa determinada área. Trata-se de olhar o aluno na sua individualidade, sem que, com isso, haja quebra de conduta ética - no sentido de se privilegiar ou favorecer algum lado - em relação aos demais alunos ou disciplinas. A decisão e tomada pelo Conselho de Classe (Carneiro, 2016)

\section{Metodologia: desenvolvendo um modelo de mapeamento}

Esta pesquisa é do tipo Estudo de Caso com abordagens quali-quantitativas. A utilização das abordagens quantitativa e qualitativa de forma associada contribui para o avanço do conhecimento no campo dos estudos organizacionais (Vieira \& Zouain, 2004). Sendo a escola uma organização/ instituição, tal consideração é aplicável a pesquisas em educação. Nesse sentido, há problemas educacionais que, para sua contextualização e compreensão, necessitam ser qualificados por meio de dados quantitativos, o que permite desmistificar preconceitos e "achômetros" sobre fenômenos educacionais, construídos apenas a partir do senso comum (Gatti, 2004).

Utilizamos como base de dados as notas dos alunos das disciplinas do curso de mineração ofertado para pessoas que concluíram o ensino médio, denominado subsequente, entre os anos de 2015 a 2019. As disciplinas foram separadas em dois grupos, conforme abaixo:

- Ténicas: as que pertencem a formação básica do profissional da área de mineração, como Tratamento de minérios, Planejamento de lavra e Topografia.

- Suporte: as que não são afins a área de mineração, mas servem como base para as disciplinas técnicas como Física, Química e Matemática.

Para cada disciplina foi criado um código numérico de forma a preservar as informações confidenciais da instituição, a saber: D1, D2, D3, D4, D5, D6, D7, D8, D9, D10, D11, D12, D13, D14, D15.

O primeiro passo foi selecionar uma ferramenta de análise estatística que fornecesse gráficos descritivos para facilitar a comparação entre notas. Para tal, foi utilizado o pacote seaborn da linguagem de programação python, ambos softwares livres, o qual possibilitou gerar o gráfico tipo boxplot, também chamado de diagrama de caixa é útil para revelar o centro, a dispersão e a distribuição dos dados, além da presença de outliers. Como exemplo, suponha que em uma sala de aula contendo 8 alunos, as notas desses sejam organizadas em ordem crescente, sendo a menor nota igual a 57 pontos, o segundo e o terceiro aluno obtiveram a nota igual a 60 pontos, a nota do quarto foi igual a 63 pontos, o quinto e o sexto aluno tiraram 66 pontos, a nota do sétimo foi igual a 69 pontos e a maior pontuação foi igual a 75 pontos, conforme a Tabela 1 .

Tabela 1. Exemplo de dados do boxplot. Fonte: Os autores

\begin{tabular}{c|c|c|c|c|c|c|c}
\hline Mínima & $2^{\mathrm{a}}$ & $3^{\mathrm{a}}$ & $4^{\mathrm{a}}$ & $5^{\mathrm{a}}$ & $6^{\mathrm{a}}$ & $7^{\mathrm{a}}$ & Máxima \\
\hline 57 & 60 & 60 & 63 & 66 & 66 & 69 & 75 \\
\hline
\end{tabular}

O primeiro quartil consiste na posição referente a $1 / 4$ dos valores, que corresponde a nota 60 da quarta posição; a mediana ou ponto médio refere-se a posição $2 / 4$, porquanto é a nota 63 , o terceiro quartil é o valor referente a $3 / 4$, nota igual a 66 pontos, e quarto quartil é o máximo valor, 75 
pontos. Seguem as definições necessárias para o entendimento do boxplot:

Para um conjunto de dados, o resumo dos cinco números consiste no valor mínimo, no primeiro quartil, Q1, na mediana (ou segundo quartil, Q2), no terceiro quartil, Q3, e no valor máximo. Um diagrama de caixa (ou diagrama de caixa e bigode) é um gráfico de um conjunto de

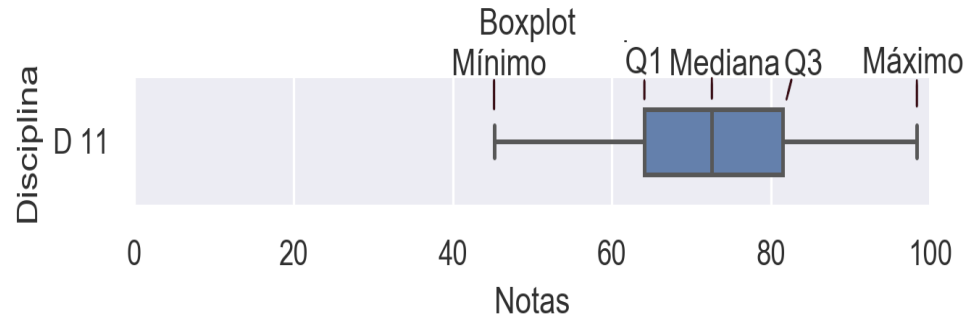

Figura 1. Diagrama de caixa das notas dos alunos da Disciplina D 11 Fonte: Próprios autores

dados que consiste em uma linha que se estende do valor mínimo ao valor máximo, em uma caixa com linhas traçadas no primeiro quartil, Q1, na mediana e no terceiro quartil, Q3 (Triola, 2017). (Veja Fig. 1).

Outro gráfico que é possível analisar a variação e a média das notas é a que contém as curvas das distribuições das notas de cada disciplina, conforme a Figura 2, mas as curvas da maioria das disciplina se sobrepõem dificultando uma análise de cada curva, para tanto, seria necessário realizar uma imagem de cada disciplina para não gerar a sobreposição. Mas é possível perceber que a disciplina D 7, cor rosa, possui sua média próxima do valor 80 , com a maioria das notas próximas deste valor, conforme a curva mais acentuada desta disciplina no gráfico.

\section{Resultados e discussão}

Definida a metodologia, foi construído o gráfico com múltiplos boxplot, no qual cada boxplot representa as notas de cada disciplina entre os anos de 2014 a 2019. Conforme o gráfico da Figura 2, o valor mínimo é igual a 45,2; o primeiro quartil é igual a 63,4 , a mediana igual a 72,2, o terceiro quartil é igual a 81,1 e o valor máximo igual a 98,3 . Assim, por meio da imagem, é possível realizar comparações entre as disciplinas técnicas quanto ao grau de dificuldade dos alunos, sendo fonte de informação para analisar as possíveis causas dos valores médios das notas serem baixos.

A Figura 3 é constituída por dois gráficos boxplot, sendo o eixo vertical referente ao código da disciplina que pertence ao boxplot imediatamente acima, e o eixo horizontal referente a nota, sendo a disciplina D 6 com menor valor da média das notas em relação a disciplina D 7. Outra análise importante de cada boxplot é a dispersão dos valores das notas, que pode ser verificada pela extensão do boxplot ao longo do eixo horizontal, mas pode ser calculada como a diferença entre o valor do terceiro quartil e o valor do primeiro quartil $\left(Q_{3}-Q_{1}\right)$. Assim, a disciplina D 6 possui maior dispersão, valor igual a 15 pontos. Quanto a disciplina D 7, a mediana possui um valor maior que 80 pontos e a dispersão é pequena, podendo gerar várias hipóteses sobre o aprendizado, como a melhor assimilação do conhecimento e uma maior homogeneidade do aprendizado-Outra hipótese é um menor grau de dificuldade das atividades avaliativas. Portanto, a

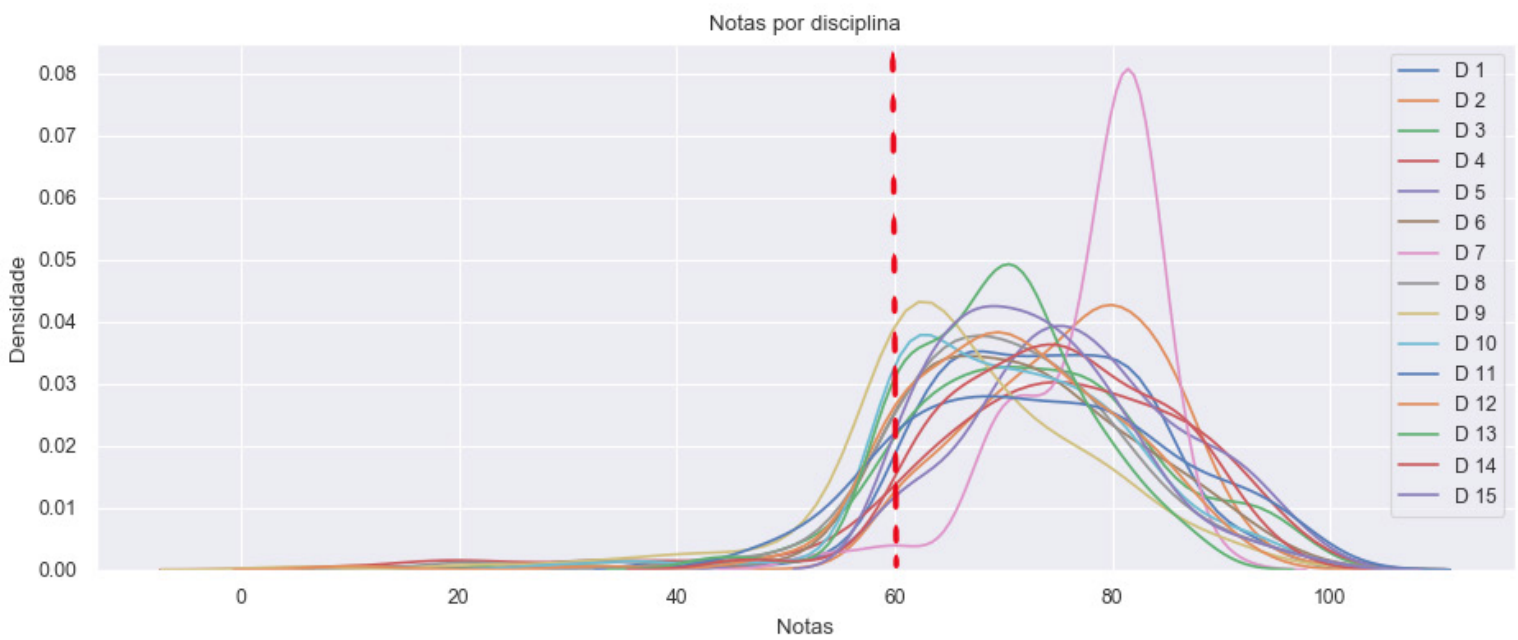

Figura 2. Histograma das notas das disciplinas técnicas Fonte: autores

\begin{tabular}{c|c|c|c|c|c}
\hline C Terrae Didat. & Campinas, SP & v.16 & $1-7$ & $\mathrm{e} 020039$ & 2020 \\
\hline
\end{tabular}




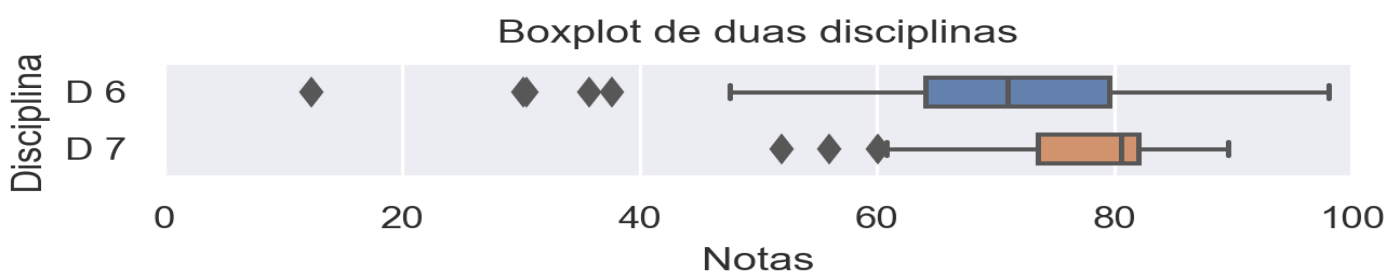

Figura 3. Boxplot de cada disciplina técnica técnica Fonte: Próprios autores

partir da medida de dispersão e de tendência central (média ou mediana) é possível classificar cada disciplina em um dos quadrantes do mapa da Figura 3.

Conforme a Figura 5, que informa o boxplot de cada disciplina técnica do curso subsequente de mineração, nota-se a disciplina D9 cuja média é igual a 66,1 existem vários pontos abaixo desse valor, ou seja, seu nível de reprovação é aproximadamente $25 \%$, pois o valor do $1^{\circ}$ quartil é 60 , e a dispersão das notas é alta. Várias hipóteses podem ser levantadas, conforme o mapa da Figura 4, sobre o processo de aprendizado obtido. A Figura 6 contém o mapeamento de cada disciplina, e uma vez que a D9 está mais próxima da região de alta reprovação, é importante realizar ações para entendimento melhor sobre o baixo desempenho dos alunos ao longo de 5 anos.

Decidiu-se realizar o gráfico que contém o boxplot das notas da disciplina D9 para cada semestre do período entre os anos de 2015 e 2019.Ao analisar o histórico dos valores das notas da disciplina D9 conforme a Figura 7, nota-se que, com exceção do $1^{\mathrm{a}}$ semestre de 2015 e 2016, os valores medianos das notas estão próximos do valor de 60 pontos, o mínimo para a aprovação e, conforme o mapa da Figura 4, as hipóteses são de baixa taxa de apropriação do conhecimento dos alunos, alto índice de reprovação e dificuldades do processo de ensino-aprendizagem. O mapeamento dos semestres da disciplina D9, Figura 8, confirma os resultados contidos na Figura 7, enfatizando um semestre que a média das notas foi abaixo de $60,2^{\circ}$ semestre de 2016, e outros que ficaram bem próximo do valor mínimo de aprovação, $1^{\circ}$ semestre de 2017, 2018 e 2019.

A disciplina D7 (Fig. 6) é o extremo da disciplina D9, devido a baixa dispersão e a maior média das notas. É interessante realizar uma análise temporal desta disciplina de maneira a analisar possibilidades do ensino e aprendizado. A Figura 9 informa o boxplot das notas de cada semestre da disciplina D7, que é uma disciplina introdutória do Curso Técnico de Mineração, implantada no $1^{\circ}$ semestre de 2018, e tem por finalidade apresentar os principais temas do curso aos alunos ingressantes, conquan-

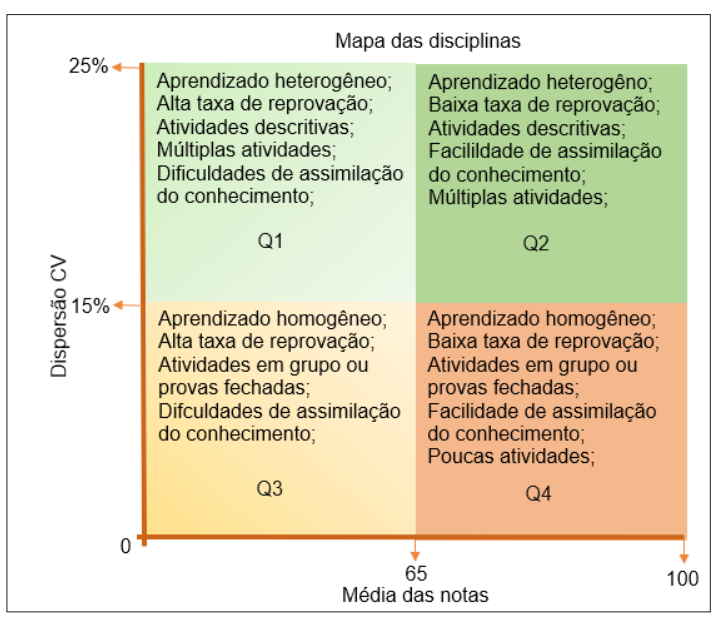

Figura 4. Mapeamento das disciplinas Fonte: Próprios autores

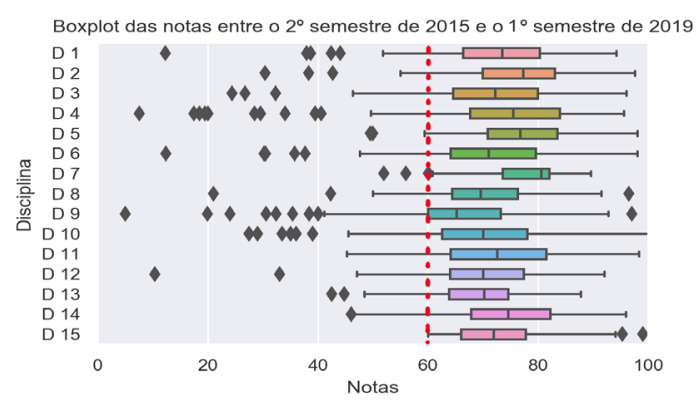

Figura 5. Gráficos boxplot das notas das disciplinas técnicas. Fonte: Os autores

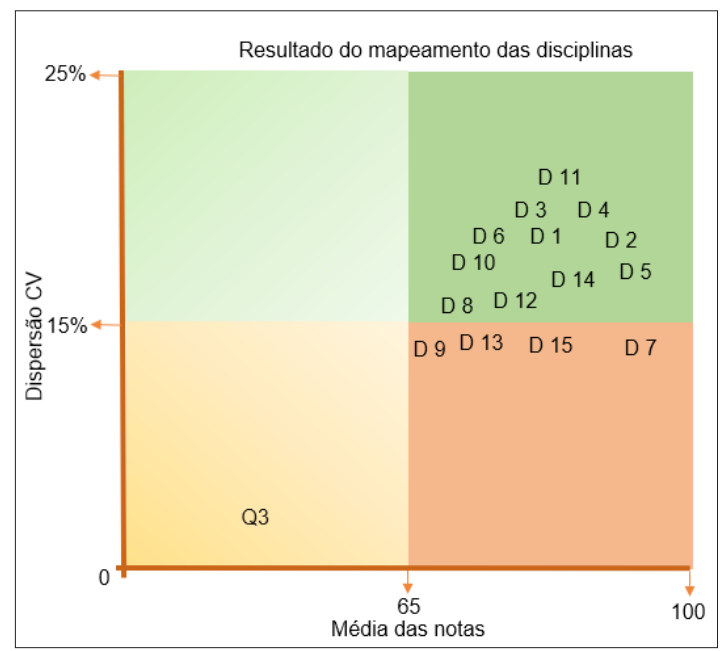

Figura 6. Resultado do mapeamento das disciplinas técnicas. Fonte: Os autores 


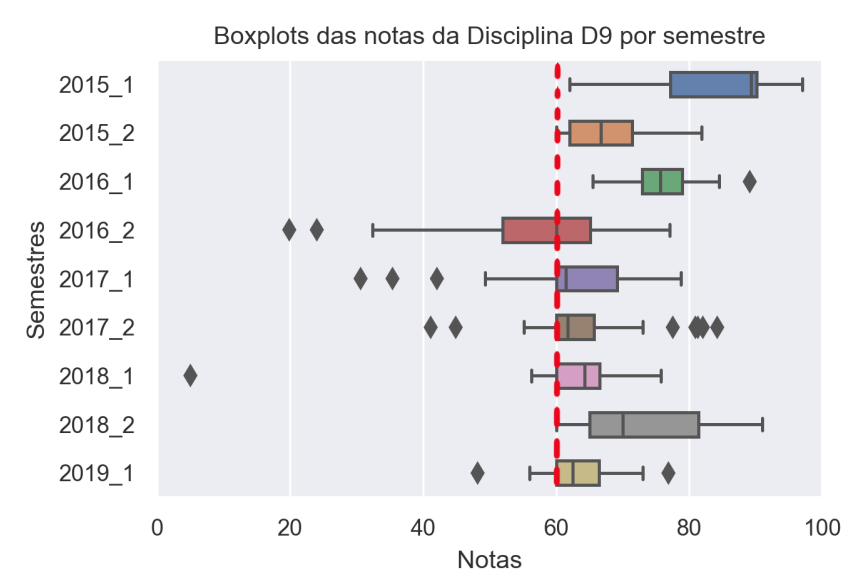

Figura 7. Gráficos tipo boxplot das notas da disciplina D9. Fonte: Os autores

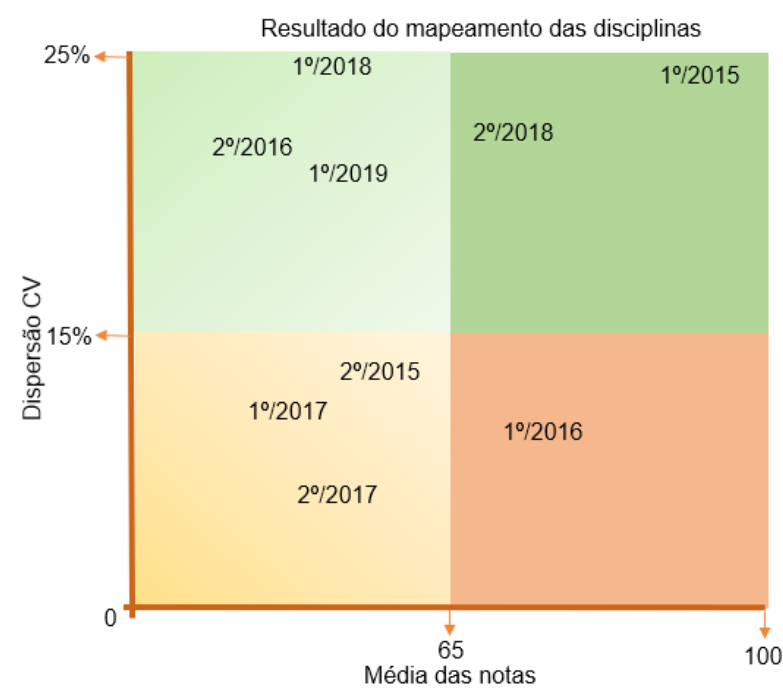

Figura 8. Resultado do mapeamento de todos os semestres da disciplina D9. Fonte: Os autores

Boxplots das notas da Disciplina D7 por semestre

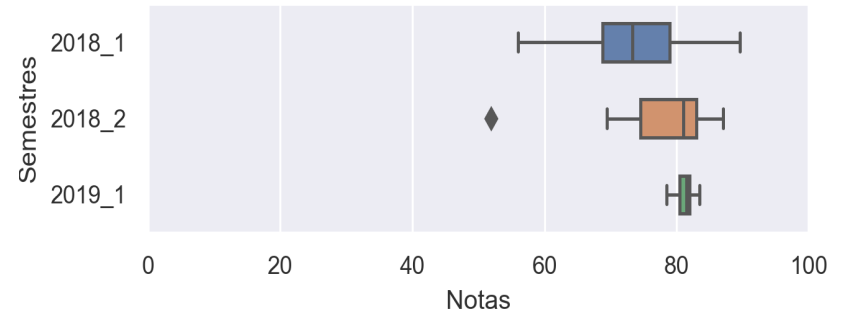

Figura 9. Gráficos tipo boxplot das notas da disciplina D7. Fonte: Os autores

to o grau de exigência desta disciplina é menor e tem-se por principal objetivo motivar os alunos.

Todas as turmas da disciplina D7 foram mapeadas no quadrante 4 de acordo com a Figura 10, ou seja, com baixa dispersão e notas médias altas.

A partir do mapeamento estatístico das disciplinas é possível realizar algumas ações para ana- lisar os motivos do baixo rendimento dos alunos em algumas disciplinas. É importante a atuação do setor de ensino no apoio ao docente para compreender os motivos dos resultados apresentados, propondo intervenções de formação continuada, por exemplo. De modo específico, a equipe pedagógica e os membros do Conselho de Classe podem fundamentar suas discussões quanto aos resultados dos alunos e quanto às estratégias para melhorar o processo ensino-aprendizagem, propondo reflexões a respeito do planejamento, das metodologias e dos instrumentos de avaliação utilizados. Desta forma, durante um Conselho de Classe é possível que as tomadas de decisões sobre aprovações ou reprovações sejam embasadas pelo mapeamento proposto neste artigo, que auxiliam a compreender as tendências das notas de cada disciplina.

\section{Conclusões}

Por meio dos resultados apresentados em gráficos tipo boxplot foi possível analisar dois parâmetros numéricos, a média e a dispersão das notas, de todas as disciplinas em apenas uma figura. Assim, foi possível demonstrar a possibilidade da ocorrência de grandes variações históricas das notas entre diferentes disciplinas, e para uma mesma disciplina. Conforme os resultados apresentados na Figura 7 para a Disciplina 9, na qual em um intervalo de um semestre, a média das notas foi reduzida de aproximadamente 78 pontos $\left(1^{\circ}\right.$ semestre de 2016$)$ para 60 pontos $\left(2^{\circ}\right.$ semestre de 2016).

O processo de ensino e aprendizado é dinâmico e sempre é necessário buscar novas formas de compreendê-lo. Portanto, a ciência da estatística pode ser utilizada para criar diagnósticos sobre as hipóteses levantadas na metodologia proposta neste artigo. Assim, é possível que as tomadas de decisões dos conselhos de classe sejam mais coerentes com o desenvolvimento do aluno ao longo do trimestre e/ou ano letivo na perspectiva de um processo de avaliação a serviço da aprendizagem.

Os resultados numéricos devem ser justificados e compreendidos pelos docentes em uma dimensão qualitativa, uma vez que podem apresentar diversos valores conforme a metodologia de ensino, forma de avaliação e contexto de vida do corpo discente.

Por fim, a contribuição do presente ensaio é a de que outras escolas possam utilizar a metodologia desenvolvida no IFMG Campus Congonhas para 


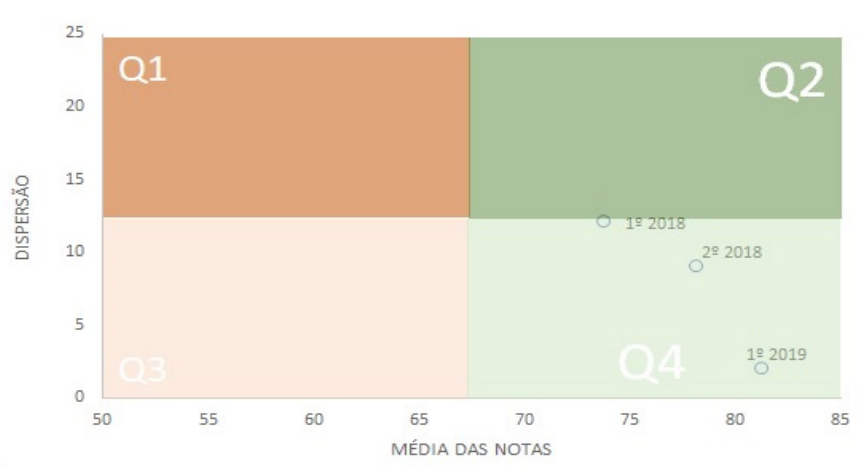

Figura 10. Mapeamento de todos os semestres da disciplina D7. Fonte: Os autores

fundamentar estatisticamente a tomada de decisões considerando a dimensão formativa e processual da avaliação. Cabe destacar a importância de uma base de dados disponível em sua integridade, contendo informações atualizadas de notas, frequência, evasões, além do contexto socioeconômico dos alunos.

\section{Referências}

Carneiro, C. W. A. (2016). O conselho de classe como ferramenta de avaliação escolar: um estudo da atuação do conselho de classe do IFPI, Campus de Parnaíba numa perspectiva ética e democrática. São Leopoldo: Faculdades EST São Leopoldo, 21p. (Dissertação de mestrado em Teologia). URL: http://dspace.est.edu.br:8080/ jspui/handle/BR-SIFE/736. Acesso 10.03.2020.

De Landsheere, G. (1976). Avaliação contínua e exames: noções de docimologia. Coimbra: Almedina. 57p.

Depresbiteris, L. (1989). O desafio da avaliação da aprendizagem: Dos fundamentos a uma proposta inovadora. São Paulo: EPU. 104p.

Gatti, B. A. (2004). Estudos quantitativos em educação. Educação e Pesquisa, 30(1), 11-30.

Guerra, M. G. (2006) Conselho de classe: que espaço é esse?. São Paulo: Dep. Linguística. Pont. Univ. Católica
São Paulo (Dissert. mestrado em Linguística Aplicada e Estudos da Linguagem).

Brasil. Ministério da Educação. (1996). Lei no 9.394 de 20 de dezembro de 1996, que estabelece as diretrizes e bases da educação nacional. URL: http://portal.mec. gov.br/seesp/arquivos/pdf/lei9394_ldbn1.pdf. Acesso 15.03.2020.

Ledesma, M. R. K., \& Schon, C. K.(2008). Avaliação da aprendizagem. In: Portal da Educação do Estado do Paraná. URL: http://www.diaadiaeducacao. pr.gov.br/portals/pde/arquivos/2516-8.pdf. Acesso 28.02 .2020

Leite, L. I. (2012). Conselho de classe: a historicidade de uma prática entre fazeres ordinários da escola. Curitiba: Setor de Educação. Univ. Federal Paraná. 18p. (Tese Doutorado)

Luckesi, C. (1995). Avaliação da aprendizagem escolar: estudos e proposições. 2 ed. São Paulo: Cortez. 184p.

Magnata, R. C. V.; dos Santos, A. L. F.(2015). Avaliação formativa da aprendizagem: A experiência do conselho de classes. Estudos em Avaliação Educacional, 26(63), 768-802.

Mattos, C. L. G.(2005). Avaliação da aprendizagem escolar e a construção do fracasso escolar. Educação $e$ Pesquisa, 31(2), 215-218.

Oliveira, J. M., \& Medeiros, C. C. C. (2018). Categorias do juízo professoral: Entre interpretações, julgamentos e implicações. Estudos em Avaliação Educacional, 29(72), 701-737.

Ristoff, D. I. (2003). Algumas definições de avaliação. Revista de Avaliação da Educação Superior, 8(2). URL: http://periodicos.uniso.br/ojs/index.php/avaliacao/ article/view/1220.

Rocha, A. D. C. (1986). Conselho de classe: burocratização ou participação? Rio de Janeiro: Francisco Alves. 26p

Triola, M. F. (Org). (2017) Introdução à estatística. 10 ed. Rio de Janeiro: LTC. 98p.

Vieira, M. M. F., \& Zouain, D. M. (orgs.). (2004) Pesquisa qualitativa em administração. Rio de Janeiro: FGV. 224p. 